\title{
TEACHING STATISTICS: CREATING AN INTERSECTION FOR INTRA AND INTERDISCIPLINARITY
}

\author{
ANNIE SAVARD \\ McGill University, Canada \\ annie.savard@mcgill.ca \\ DOMINIC MANUEL \\ McGill University, Canada \\ dominic.manuel@mcgill.ca
}

\begin{abstract}
Statistics is taught in mathematics courses in all school levels. We suggest that using rich tasks in statistics can develop statistical reasoning and create both intra and interdisciplinary links in students. In this paper, we present three case studies where middle school mathematics teachers used different tasks in lessons on pie charts. We analyzed the actions implemented/performed/attempted by teachers to support the development of statistical reasoning and the creation of intra and interdisciplinary links in their lessons. Results show that their procedural vision of statistics led them to focus more on graphical representation, neglecting aspects of statistical reasoning. Results also reveal an interdisciplinary intersection between mathematics and statistics, which may prevent the development of statistical reasoning.
\end{abstract}

Keywords: Statistics education research; Statistical reasoning; Teaching; Middle school

\section{INTRODUCTION}

In the 21st century, citizens should be able to solve complex problems that cannot always be done by applying one strategy or a particular algorithm. More creative approaches that require using high cognitive level thinking are needed in order to bring solutions to these problems. Do students have the necessary opportunities to develop the abilities needed to adapt themselves and be productive citizens in their society? Do they have the opportunities to develop their mathematical competencies along with citizenship competencies (Savard, 2014)? We argue that students should be exposed to rich tasks in mathematics and statistics classrooms in order for them to be better prepared to face the realities and problems in society. Such tasks include problems that are open-ended (have multiple answers and be solved using various strategies); complex (require multiple steps to find answers, require investigation of a particular situation or posing a question to investigate, require making choices and justifying them, or require finding patterns, generalizing, and proving results); ill-defined (missing necessary data, prompting students to search or define them to find answers); have different interpretations; and are contextualized (Manuel, 2010; Manuel, Freiman, \& Bourque, 2012). However, mathematics and statistics are still often taught in a way in which students focus on developing procedural understandings of concepts. Using traditional teaching methods

Statistics Education Research Journal, 15(2), 239-256, http://iase-web.org/Publications.php?p=SERJ (C) International Association for Statistical Education (IASE/ISI), November, 2016 
tends to have students see mathematics as a school subject that consists of rules, formulas, equations and algorithms to apply, thus not supporting them to make links between mathematics and the world or different mathematical concepts (Boaler, 2009). In fact, little seems to be known about the explicit intra and interdisciplinary links teachers and students make while implementing those tasks (Mousley, 2004). Yet, emphasizing links between mathematical ideas is considered an important feature of meaning-oriented instruction (Knapp et al., 1995). Those links should be part of the curriculum, and teachers are expected to be aware of them (Ball, Thames \& Phelps, 2008).

In this paper, we examine how three francophone middle school teachers from Québec (QC) and New Brunswick (NB) supported students in developing statistical reasoning and in making interdisciplinary links between statistics and mathematical concepts or other contexts, and between various mathematical concepts involved in the process. The teachers taught a lesson on pie charts and used different tasks in their lessons. We also examine the teachers' representations of statistics to investigate if such representations guided their actions during the lesson, and thus to determine their goals when teaching statistics. We define representations as an intersection between a situation and the knowledge mobilized by a person according to that situation (Brun \& Conne, 1990). It is an interpretation of a situation, based on the person's knowledge (Savard \& DeBlois, 2013). Representations allow evocation and anticipation of something that is not immediately perceptible (Piaget, 1976). With these ideas in mind, the following questions guided our study:

1. How did the teachers support the development of statistical reasoning in their lessons?

2. What intradisciplinary and interdisciplinary links did these teachers create in their lessons?

3. What are these teachers' representations of statistics?

\section{THEORETICAL FRAMEWORK}

\subsection{TEACHING STATISTICS FOR DEVELOPING STATISTICAL REASONING AND CITIZENSHIP COMPETENCIES}

Statistics is a part of the mathematics curriculum for both Quebec (QC) and New Brunswick (NB). Note that each Canadian province has its own curriculum. Both curricula align with the National Council of Teachers of Mathematics (NCTM) standards for statistics, which focus on exposing students to a statistical approach in which students from K-12 should develop the abilities to: 1) formulate questions that can be addressed with data and collect, organize and display relevant data to answer them; 2) select and use appropriate methods to collect data; and 3) evaluate inferences and predictions based on data (NCTM, 2000). Throughout this progression, guidelines in curricula have the aim that students will be able to use descriptive statistics in order to make informed decisions. Critical thinking is thus an important aspect to be developed. In fact, the broader goal for teaching statistics is to develop citizenship competencies in all students, such as being able to "participate effectively in an information-laden society" (Gal \& Garfield, 1997, p. 2). To do so, Gal and Garfield (1997) identified eight goals that go beyond mastering statistical processes and help to construct a larger picture of how, when, and why to use statistics:

1. Understanding the purpose and logic of statistical investigations;

2. Understanding the process of statistical investigations;

3. Mastering procedural skills; 
4. Understanding mathematical relationships;

5. Understanding probability and chance;

6. Developing interpretive skills and statistical literacy;

7. Developing the ability to communicate statistically; and

8. Developing useful statistical dispositions.

To support the development of statistical reasoning, it is important that teachers ask "how" and "why" questions. Students must explain their reasoning and justify their use of statistical concepts (delMas, 2002). Thus, teaching to support statistical reasoning is more than teaching basic literacy (identifying, describing and interpreting) or thinking (applying, critiquing and evaluating) (delMas, 2002). Pratt, Davies and Connor (2011) argued that students can also develop statistical reasoning using technology.

In accordance with the broader goals that teaching statistics develop citizenship, Savard (2008) developed a model that highlights how mathematics or statistics might develop critical thinking and decision-making competencies. By using mathematics and/or statistics to study a phenomenon coming from a sociocultural context, learners situate themselves in a mathematical and/or statistical context. It is possible to use the new knowledge constructed in this context to develop critical thinking toward the phenomenon studied. Critical thinking might be used to make judgments using criteria, taking into consideration the context and by using self-assessing thinking in order to validate the reasoning process (Lipman, 1995). It is also possible to use critical thinking when solving statistical problems. Wild \& Pfannkuch (1999) portrayed a fourdimensional model of statistical thinking. The third dimension of the model can be seen as a critical thinking process used in the context of statistics. Thus, the interrogative cycle is an interrogative state, where the thinker is always questioning each stage of his thinking when generating possibilities, seeking information, interpreting, critiquing incoming information and ideas, and judging the reliability of information.

This process can also be used to support the decision-making process. According to Swartz and Perkins (1990), making decisions is generating, exploring and assessing different options in order to find the best choice. This process takes into account personal characteristics, such as values and knowledge, cognitive and cultural bias, environmental variables (availability of an object for instance), and the context (Halpern, 2003). Critical thinking and decision-making are two important components of citizenship competencies (ten Dam \& Volman, 2004). Given the fact that citizenship means, among other things, to participate democratically in the society, making informed decisions is crucial.

\subsection{MAKING INTERDISCIPLINARY AND INTRADISCIPLINARY LINKS}

In light of major worldwide changes and new complex phenomena that occurred over the last decades, it is essential to take into account these social realities. To better prepare students to adapt themselves to these new realities, it is strongly suggested to include interactions between school subjects (Legendre, 1993), instead of treating them as standalone subjects (Lenoir \& Sauvé, 1998). Taking into account these interactions is defined as interdisciplinarity, and it is considered a negotiation between disciplines - where the development of one discipline contributes to the development of others (Fourez \& Larochelle, 2003). It is a productive way to help students make sense of contents and phenomena. Guidelines from the reform on teaching and learning mathematics emphasize the importance of making connections, not only between mathematical concepts, but also in different contexts that relate mathematics to other subjects, and in students' own interests and experience (NCTM, 2000). Moreover, for students to be able to make sense of mathematical and statistical ideas, they should be exposed to possible links that can be 
made within the disciplines themselves, such as conceptual and procedural understandings; the representation of ideas and processes; mathematical or other domains and ideas (Ministère de l'Éducation du QC, 2006; Ministère de l'Éducation et du Dévelopment de la Petite Enfance du Nouveau-Brunswick, 2012). Integration of contents within the same discipline is called intradisciplinarity (Samson, 2014).

In this paper, we consider that statistics and mathematics are two different disciplines, because they have different epistemologies. The reasoning behind those disciplines is not the same. Statistics focuses on an interpretative reasoning that depends on variability, and mathematics focuses on a deterministic reasoning (Savard, 2014). Statistical reasoning involves a conceptual understanding of important statistical ideas (delMas, 2004; Garfield, 2002) and could be developed using technology (Kader and Perry, 1994). However, mathematics might be used to solve statistical problems (delMas, 2004). We understand that in school systems, statistics is considered as a branch of mathematics, but in opposition to Carvalho and Solomon (2012), we do not consider that developing mathematics and statistics together is a form of intradisciplinarity, where topics or concepts in a single discipline are related to each other.

\section{METHODOLOGY}

\subsection{CONTEXT OF THE STUDY}

This multi-case study evolved from an epistemological position inspired by Maturana (1987), who claimed that everything is said by an observer. We also followed Robert, Penninckx, and Lattuali's (2012) typologies of methods using video cameras in classrooms. The study involved a multi-vocal ethnography approach (Tobin 1988; Tobin, Hsueh \& Chantalesawa, 2009) as it was conducted with teachers from two different Canadian regions: Quebec (QB) and New Brunswick (NB).

The data used for this study are part of a larger nationwide study (Reid et al., 2015) conducted from 2012 to 2015 with francophone and anglophone grades 7 or 8 mathematics teachers in four different regions of Canada: Alberta, Ontario, QB, and NB. The main objective was to describe regional differences in mathematics teaching and underlying pedagogies in Canada, and to relate these differences to student achievement in mathematics. The objective was met via focus groups of teachers from each region reacting and discussing the practices and underlying pedagogies in lessons they previously video-recorded, and also in lessons recorded by the teachers from the other regions.

The procedure of the nationwide study involved three phases. In the first phase, each teacher video-recorded three types of lessons: a lesson that he/she described as a typical lesson for him/her, a lesson that he/she considered as an exemplary lesson for his/her classroom, and a lesson that introduced a concept related to fractions. The teachers chose the concepts taught for the typical and the exemplary lessons. The lessons were 55 or 75 minutes long, depending on the schools' policies. We edited each lesson and kept only the teaching moments when the teachers interacted with their students. Each edited video was 15-20 minutes long. The teachers were invited to participate in the editing process or to watch the video, but they declined.

In the second phase, we met the teachers in separate focus groups, depending on their language and their region. These focus groups lasted three days and the focus each day was on one type of lesson (typical, exemplary, or introductory). For both francophone groups, we added a fourth day due to uncontrollable situations that occurred during the time of the focus groups. 
During the time of focus groups, each teacher presented his/her lesson. Then, the group watched the edited video and discussed the practices and the pedagogies observed in it. During the discussions, the participants shared the practices and pedagogies they appreciated in the lesson, asked for clarifications about aspects they observed in the lesson, and offered suggestions to improve the quality of the lesson. After the four teachers watched and discussed all four lessons for each type of lesson, they selected one video that they believed best represented the type of lesson they were discussing during that day. That video was shown to the participants from the other regions. The third phase of the study consisted of watching and discussing the videos selected in the other regions.

\subsection{CASES SELECTED}

One grade 7 teacher from QC and two grade 8 teachers from NB recorded a lesson on pie charts as their typical lesson. They were the only teachers who chose a topic related to statistics. We considered that their lessons had elements of rich tasks, and so had potential for intra and interdisciplinary links. Each teacher taught a different lesson, which we present in the following paragraphs. We used pseudonyms to name them. We translated the problems given to students and the teachers' quotations from French to English.

Elsa (grade 7 teacher from QC) Because it was close to Halloween, Elsa brought small bags of colored candy to class. Each group of three or four students received one bag and had to create a pie chart representing the distribution of the colors in the bag. During the first part of the lesson, Elsa presented the task and discussed with the students the title of the pie graph. Students gave out ideas for the title and she asked the rest of the class if the title was precise. Once everyone agreed on the title, Elsa spent some time addressing what was needed to construct the pie graph. She presented the table that students needed to complete to create the pie chart. The table had columns entitled "color," "absolute frequency," "proportional frequency," and "angle."

During the second part of the lesson, each group explored their bag of colored candy and created their pie charts. During the last part of the lesson, Elsa discussed the task with the students and went over the procedure using the data from one group, the only one that had nine candies in their bag. Elsa admitted to us that she was caught by surprise. She did this activity every year and bought the same bags of candies, which always had 9 candies in the past. She was not satisfied with the fact that there were 8 candies in some bags, because the angles were too easy to determine. After the discussion, Elsa set the students some problems related to pie charts from their textbook.

Diane (grade 8 teacher from NB) Diane teaches in a technology-oriented school and uses technology as much as possible in her mathematics lessons. All the students have access to a laptop. She began her lesson with a mathematical jog, which consisted of asking ten theoretical or procedural questions on concepts they had learned throughout the year. This part did not relate to statistics, so we did not consider it for our analysis.

Diane continued with the lesson on statistics. The previous day (not recorded), she had discussed with her students the procedure to create pie charts. For this lesson, she gave them three problems to solve. She was hoping that her students would have the chance to teach one another by the end of class, but the time ran out. Before giving them the problems to solve, she reviewed some of the ideas they had discussed the day before. She directed her students to her blog, where she had posted a link to a video on creating pie charts; students could watch the video if needed. She also encouraged her students to 
get out their diagnostic tests (she gives a diagnostic test at the beginning of each trimester on the content she will cover in order to assess students' knowledge of concepts and guide her teaching throughout the trimester) and to use it as a guide.

The students had to solve the following problem (posted on her blog) individually and then compare their answers with their neighbor.

The artistic activities of Canadians are the following: photos, $46 \%$, videos, $21 \%$, drawing, $13 \%$, and dance and piano, $10 \%$ each. Draw a pie graph that represents the artistic activities of Canadians.

When the students finished solving the problem by paper and pencil, Diane gave them a second one. She mentioned that this one would serve as a formative assessment so her students handed in their work once completed so she could see who understood how to create a pie chart and who would need more support. The problem consisted of a table representing the number of students who used different means of transportation to get to school. The students had to create the pie chart using the data. The teacher also challenged the students to create two questions about the data from the pie chart. However, the students did not have to answer the questions they invented.

When the students finished the formative assessment, they would have a longer problem to solve on their laptop. The teacher posted a third problem on Google Docs. The students had to access it from their laptops and solve it. She also mentioned that it was an example of problems they could find on the final exam, which is a provincial one. The problem was as follows:

Julie will start university next September. She has a monthly budget of $\$ 1,000$. Her expenses include: $\$ 90$ for recreation, $20 \%$ for rent, 2/10 for transportation, and twenty-five hundredths for food budget. The remainder will be spent on other personal expenses. Construct a pie chart from the data above.

Diane constantly walked around the classroom while her students worked on the problems to monitor and guide them if needed. She insisted a lot on the importance of clearly communicating the process while solving the problems.

Chantale (grade 8 teacher from NB) Chantale had a lesson containing two activities. The first one was an exercise where her students divided a circle (a pie chart, according to her) into sections of different angles without using a protractor. This activity permitted her students to see the relationship between certain angles. She began her activity by reviewing prior knowledge about pie charts that they learned in previous lessons. Then she gave each student a handout containing a big circle representing a pie chart. Her students had to represent various angles on it without using the protractor. After the students had completed the task, Chantale concluded the activity with a discussion on how to divide the pie chart in order to get the desired angles.

The second activity was one that her students had begun a few days before. They created a survey question, administered it to the other students in the class, and represented the results using a pie chart. Before the students returned to work on that activity, Chantale took the time to discuss the different aspects that a pie chart should contain, putting an emphasis on making sure that they avoid bias and the importance of interpreting the results. She even gave her students a handout containing guiding information about creating, analyzing and interpreting that particular data display. She concluded the activity by talking about how to divide the pie chart without a protractor. They would continue the survey during next class. 


\subsection{DATA ANALYSIS}

We transcribed the edited lessons. We used the data corpus to analyze and interpret the teachers' interactions during those lessons that would support the development of statistical reasoning in students as well as the intradisciplinary and interdisciplinary actions related to knowledge building (Savoie-Zajc, 2000). We based our analysis on the eight instructional goals identified by Gal and Garfield (1997), as this would also cover the links made which are part of the goals. We read the corpus and looked for instances where the teacher targeted any of the eight goals and/or made explicit or implicit intradisciplinary and interdisciplinary links.

We asked the teachers about their representations of statistics during the focus groups. The content of those focus groups was also transcribed. We looked over the teachers' answers to that question, attempted to find a relevant theme that would best describe the key elements in the answers, and compared them with the NCTM (2000) standards.

\section{RESULTS}

\subsection{INSTRUCTIONAL GOALS FOR TEACHING STATISTICS}

Understanding the purpose and logic of statistical investigations No teacher addressed that goal, even though it is part of the mathematics curricula in both provinces. It is possible that this goal was targeted in previous or future lessons that they chose not to record.

Understanding the process of statistical investigations Elsa and Chantale both created instances where students could understand the process of statistical investigations. Elsa incorporated the context of studying the colors in bags of candies, and Chantale challenged her students to create a survey question and administer it to the other students in the class. However, in both cases, we were not able to observe any explicit links that would emphasize the purpose of the investigations. It is possible that Chantale did that in a previous lesson that was not recorded, as the students had already begun that activity the day before. In addition, in both lessons, it was mentioned that the data should be represented in a pie graph. This enabled students to reason about the appropriate type of data to collect and the ways to represent the data.

Chantale's task was more open-ended compared to Elsa's task, because she let her students formulate the question and collect the data on their own. At one point during the activity, she talked about bias in samples. "I have somebody that asked me if we should include me and Brigitte (a helping teacher who was in the classroom) in the sample, what do you think? What does your question ask? If you are trying to find something with students, should I be included? ... No, because then your results won't be as precise.” Elsa gave her students the data (a bag of colored candies for each group). She spent a lot of time discussing the title for the pie chart. She used a whole-class discussion for this. She asked students to give an idea of what the title could be. And then, by asking the class if the title was precise, they could all work on improving the title. Students would give ideas as to why it was not precise and suggest other formulations until everyone agreed that the title was precise. Elsa's intervention was thus more guided.

We did not observe any instance where Diane supported students in understanding the process of statistical investigations. It is possible that she did this in a previous 
unrecorded lesson. Her lesson was mainly focused on the procedure for creating pie charts.

Mastering procedural skills The major goal for each of the three lessons was for students to understand the procedure for creating pie charts. What was interesting to notice was the diversity of approaches that each teacher used. Elsa spent a whole class on this. She told her students that because they learned how to create one last year, they would not spend too much time on it. Elsa took the time before her students created the pie chart with their data (bag of candies) to go over the table that needed to be completed in order to create the graph. After students created the pie chart with their data, she used the data from one group, completed the table on the board, and made sure that students understood each step. She would ask students questions about what each column represented and how to do the proper calculations. For instance, "What does the effective fraction mean? ... How do we calculate that? ... So we take the number of red candies as the numerator, and what would be the denominator?” By doing so, she made links between the definitions of the mathematical concepts involved in the procedure. She also stressed the importance of being able to construct pie charts because she explained how she would mark their work on the final exam at the end of the year.

Diane used technologies as well as a strategy that she called "observing, practicing, and teaching" in her lessons. In a previous unrecorded lesson, she taught her students how to create pie charts. The students were able to observe how it is done. The recorded lesson was the opportunity for students to practice this, in other words, to focus on the procedure of creating pie charts. Diane also seemed to put an emphasis on students developing good work methods and being responsible for their learning. She placed a video on her blog that showed the procedure to create pie charts so that students who needed guidance could consult it. This video (available at https://www.youtube.com/watch?v=W92d285tYy4) is approximately 10 minutes long and only shows the procedure for creating the graph. Nothing is mentioned about when or why we could use one. She also told her students to consult the diagnostic evaluation that they did at the beginning of the trimester, because it was also a good guide.

In Chantale's case, part of her lesson focused on creating pie charts without using a protractor. She wanted her students to be able to represent particular angles on the graph based on the relations between angles and fractions. She asked her students to practice this skill and at the end, she invited a student to show his work. She even went over the steps for getting angles. "For $180^{\circ}$, we divide the circle in 2 . And for $90^{\circ}$, we do the same but on the other end ..."

Understanding mathematical relationships In the last part of the lesson, Elsa talked about the absolute frequency (the number of candies of a certain color in a bag), the proportional frequency $(\mathrm{a} / \mathrm{b})$ for each color of candy (frequency expressed as a fraction), and the relative frequency (as a percentage). She made links between numbers, fractions, and percentages. She reminded students that the total should be found by adding the absolute frequency of each color.

For the proportional frequency (a/b), Elsa came back to the definition of a fraction. She asked the students why we write 3/9 and made it clear that 3 was the number of red candies and 9 was the total number of candies in the bag. At the very end, she asked the students how to fill in the relative frequency column of the table though she did not give much importance to it. Elsa focused her lesson on the representation and the organization of data using mathematical notations. When it came to the idea of constructing a pie chart, Elsa made links between fractions, the circle and angles. She asked her students 
what they knew about a circle. They answered that it had a 360-degree angle. Following that, she asked her students how to determine the angle of the sectors for each colored candy in the pie graph. A student answered that "for the red candy, you can do 3/9 of 360." Elsa made it clear that they could use fractions in other contexts. She claimed the following: "It is not for nothing that we discussed fractions, fractions of a number and so on previously. Now you see that we can apply fractions in contexts other than in arithmetic.”

Elsa then went over different strategies of doing this calculation by saying they could use proportional reasoning. Then she did an example with the class, focusing on the strategy of dividing 360 by 9 in order to get the measure of $1 / 9$ and then multiplying the quotient by 3 . She proceeded that way because a student suggested that strategy. Elsa guided her teaching according to the strategies brought up by her students. She would even question students on the procedure. For instance, she asked, "why would we divide 360 by 9 ? ... Oh ok, so you are saying that by doing so, it will give us what is the amount of $1 / 9$. And then if we have $3 / 9$ for our color, we only have then to multiply by 3 . Do you all understand this strategy? We used this one often when we were working with fractions.”

Diane focused her attention more on the procedure of constructing pie charts and the calculations involved, and did not make any specific links between the mathematical concepts involved in the procedure. For instance, Diane supported students who struggled with changing angles into degrees, finding fractions of a number, such as $2 / 10$ of $\$ 1,000$ and transforming quantities into degrees (angles). She would question students to support them in understanding why they use particular algorithms, but she didn't make any links between the concepts involved. "The word 'of', it means a multiplication right. So you are multiplying 2 fractions here. How do we multiply fractions again? ... Yes that's it, we multiply the numerators and the denominators.” The entire lesson focused on making calculations for constructing pie charts. It is possible that some links were made during the previous lesson, but we cannot be sure of this as that lesson was not recorded. The part of the lesson Diane recorded focused more on practicing.

Chantale took the time in her lesson to question her students about prior knowledge at the beginning and to review what they had done at the end of the class. During those question sessions, she often asked, "Why we do this?" focusing on developing statistical reasoning, as described by delMas (2002). Chantale made links between angles, percentages and the circle. However, the links between statistics and mathematical concepts were more implicit. For instance, when discussing the procedure to find the angle for a particular sector of the pie chart, Chantale asked, "Why do we use 360?" A student answered, "Because there are 360 degrees in a circle." The student seemed to be able to make the link between the statistical and mathematical ideas, but Chantale did not make that link explicit.

With the survey activity, Chantale went beyond simply using the procedure to create pie charts and set it in the context of carrying out a survey. Although the process was guided (use one question and the sample must be the other class members), students still had to create a survey question and collect, represent, and interpret the data. Because the students did not finish that activity by the end of class, we do not know if Chantale made any link between statistical and mathematical concepts when the students presented their results. Her conclusion at the end of her lesson simply focused on how to create angles without a protractor. Some links could have been made between fractions and the angles, but they were not made.

In conclusion, two out of the three teachers focused mostly on learning the procedure to create pie charts (delMas, 2004). We identified links between mathematical ideas, such 
as notation, proportional reasoning, fractions and percentages, geometrical representation and measurement. However, not all teachers made the links explicit. Elsa attempted to make links with previous concepts taught in class, and Diane tended to give the ideas separate identities. Chantale questioned students so they understood why we apply certain concepts, but the links were not made explicit.

Understanding probability and chance We did not observe any instance where the teachers made links with probability and chance in their lessons, even if the lessons provided opportunities. However, during the discussion group, the teachers suggested to Elsa that she could go further with her activity and introduce the idea of probabilities. A teacher mentioned that she could make totals with all the class data, and based on the results they could determine the probability of specific elements. This could have been a good opportunity to bring up the variability in the data.

Developing interpretive skills and statistical literacy Elsa did not get her students to interpret the data. She simply focused on the procedure of representing the data with a pie graph. After she finished constructing the pie graph on the board, she ended her lesson and asked the students if they had any questions. When there were none, she gave her students a few problems to solve in the textbook. It seemed that Elsa's focus was on creating a pie chart correctly, because during the discussion she put a lot of emphasis on how she corrected this type of question on assessments and what she needed to see to be able to give marks. It is possible that she chose this action because there were less than ten minutes remaining at the end. During the discussion group, the other members noticed the fact that she did not spend time on the interpretation of data (NCTM, 2000) and they made that suggestion to her. The other members mentioned that, for example, they could have compared the data between groups, they could have made a set of data of the whole class and then seen how the data from each group was similar to and different from the whole class data, and to make links with probability, business, economics, and other fields that would be interesting to discuss. In conclusion, Elsa focused her lesson on the idea of representing data (NCTM, 2000). No inference or predictions were made based on the data.

Diane did put an emphasis on interpreting data as she challenged her students to create questions about the data on the pie chart for the formative assessment task. Students must be able to interpret the data in order to create questions. However, we did not have the students' work to make any conclusions regarding effectiveness. When we discussed her lesson during the focus groups, we questioned her about this. However, she didn't remember what she did with the questions. She recorded the lesson seven months prior to the meeting and did not remember what she did because she uses different approaches with her students. During the discussion group, Diane did realize that she did not put enough emphasis on interpreting data. She acknowledged that, instead of just having students create a question, she could also have asked them to draw conclusions about the data. Basically, Diane, just like Elsa, focused her lesson on the idea of representing data (NCTM, 2000). No inference or predictions were made based on the data.

However, Chantale had a perfect opportunity to have students interpret data with the survey activity. Students had to go through the process of selecting a question, which was part of their interests, collecting, displaying, and interpreting data. The question was related to another subject. Chantale seemed to focus on the process involved and the interpretation of data. In addition, not only did she hand out a guide about what a pie chart must contain so it would be clear to everyone, that guide contained items to 
consider while interpreting the data. Because the students did not have the chance to finish this activity before the end of class, we do not know if Chantale made links between statistics and other contexts. It is possible that she did at the conclusion of the activity that was not recorded.

Developing the ability to communicate statistically There was one instance in Diane's lesson where we noticed a link between language skills (French) and mathematics. When the students worked on the problem on Google Docs, she mentioned, "This is where I can see if you can do French along with mathematics at the same time." This comment was related to the fact that students would have to be able to understand the problem in order to solve it as the text was longer. They needed to be able to interpret the content of the problem in order to represent the data. There were no instances where students had to communicate specific statistical data or visual representations.

Developing useful statistical dispositions We only observed one instance where Chantale discussed biases with the data. We discussed that part in the second goal.

\subsection{TEACHERS' REPRESENTATIONS OF STATISTICS}

When analyzing the responses given by our participants during the focus groups, we noticed that each of them had a clear representation of statistics. However, all of their representations were different. We were able to recognize a theme for each of their representations: displaying data collected, highlighting data, and data as needs or trends in society.

Displaying data collected Elsa had a clear representation in mind: "My representation of statistics is to be able to represent and compare the data. In this activity, I wanted them to be able to use the data and create a graph with it." However, when related to the three ideas of statistics propounded by the NCTM (2000), we noticed that the ideas of evaluating inferences and making predictions were not in her representations. She saw statistics as a way to collect, organize, represent and analyze data, although the question was built with the class at the beginning of the lesson and she didn't spend time analyzing the data at the end of her lesson. She didn't mention the ideas about formulating questions in her representation of statistics. However, in the first part of her lesson, we observed that she took time to discuss the importance of creating clear and rigorous titles for graphs. The classroom had a small debate on this aspect. They struggled a bit with creating the title. Elsa would often ask if the idea proposed was a good title or not. In conclusion, Elsa showed a procedural vision of statistics, and her lesson focused on a graphical representation and thus led her to avoid strong statistical reasoning development on the stochastic process (delMas, 2004; Garfield, 2002).

Highlighting data Diane also had a clear representation in mind. To her, statistics was a branch of mathematics: "To interpret numbers, to make situations speak, to make diagrams speak, to use them to explain certain things." However, in her lesson, she only focused on displaying data. In all the tasks, the data were given to the students. We could argue that she focused on interpreting data when she challenged her students to invent two questions about the data. We did not have access to the necessary data to make this specific claim. In conclusion, although Diane's goals for her lesson were aligned with the NCTM (2000) standards, like Elsa, the ideas of making predictions and inference were missing from her representations. She saw statistics as data given to students in order to 
display them and compare some of them. She also showed a procedural vision of statistics and her lesson did not offer opportunities for students to develop statistical reasoning.

Data as needs or trends in society Chantale's representation of statistics was more general. To her, statistics was something to use to explain needs in society or to find trends in something. "So statistics, it helps you to know the needs of a certain population. Or not only that, but also to see what is more 'à la mode', so what is more popular." This could be related to statistical reasoning, where focusing on why supports the development of statistical reasoning (delMas, 2002). It is possible that the survey activity aligned itself with her representation of statistics. For instance, the questions created by her students could have been needs for which they wanted to find answers. The results would also determine the distribution of the different answers, so we could see what type of data is more popular. However, we did not have the necessary data to make conclusions. Her lesson was designed to support the development of statistical reasoning, because she wanted them to answer the 'why'.

\section{DISCUSSION}

In the introduction, we argued that using rich tasks in statistics lessons could promote both the development of statistical reasoning and the creation of intra and interdisciplinary links in students. All three teachers used tasks in their lessons. Diane mostly used problem solving in her lessons. Elsa and Chantale both used more inquirybased learning tasks, in other words, tasks in which students investigated a particular context. As we mentioned in the results, Elsa's task was more structured as she guided students in following the appropriate steps, and Chantale's task was more open-ended as students were able to create their own survey question.

Our results show, however, that the opportunities to develop statistical reasoning and to make intra and interdisciplinary links were missed. We further discuss these results in the following sections.

\subsection{THE DEVELOPMENT OF STATISTICAL REASONING}

The eight instructional goals for statistical reasoning are opportunities to explore different contexts. For instance, the actions taken for targeting goals 1, 2, 3, 5 and 7 are situated in a statistical context. This is a context where statistical reasoning is dominant. Instructional goal 4 also presents a statistical context, but it includes a mathematical context as well. Our three teachers did present statistical tasks, but they focused on the mathematical content in them. In fact, they only focused on the mathematical context, leaving alone the sociocultural and the citizenship contexts according to Savard's (2008) model. The other two contexts are also present in some of the instructional goals. For instance, instructional goal 6 consists of using the results developed in the statistical context to look back into the sociocultural context. Instructional goals 7 and 8 are part of the citizenship context, where the statistical reasoning developed in the statistical context is applied for participating in the society.

The results of our study suggest that the most common instructional goals for teaching statistics are the ones that focus more on the procedural aspects of statistics, more specifically on the representation of data (instructional goal 3). This appears to be the same situation for the links teachers made during the lessons. Those links might be presented to students in a procedural way (Garfield, 2002). Our three teachers did focus 
on the construction of a pie chart, using mathematical knowledge. This supports the development of statistical reasoning, but it is not enough for developing it in a deep and meaningful way because the focus of the lessons was on elements of basic literacy rather than explaining and justifying the process (delMas, 2002).

\subsection{INTRADISCIPLINARY AND INTERDISCIPLINARY LINKS}

Our results suggest that although the teachers taught a lesson on statistics, the statistical context itself was not really present. Elsa focused mainly on the mathematics involved in her statistical lesson, and Diane and Chantale made implicit links with mathematics. In all the cases, the teachers focused on the mathematical context and then created an intersection between the mathematical and the statistical contexts. Thus, the concepts presented by the three teachers belonged to mathematics (angles, fractions, percentage, circle), but were used for creating statistical displays, in this case a pie chart. This finding suggests that making pie charts cannot be done in the statistical context alone. It could be true for making other displays as well as for making inferential statistics. For example, some mathematical concepts are required to calculate the average or standard deviation. In fact, an effective statistical lesson should be situated in the intersection of mathematical and statistical contexts, where the content of the intersection might be developed instead of mathematics and statistics as two separate disciplines. Focusing on mathematics in a statistical lesson might create an obstacle to developing the eight instructional goals, which are aimed at developing statistical reasoning for improving citizenship competencies. It thus suggests that statistics should be interdisciplinary by nature: mathematics and society are needed. Figure 1 presents the interdisciplinary intersection between mathematics and statistics.

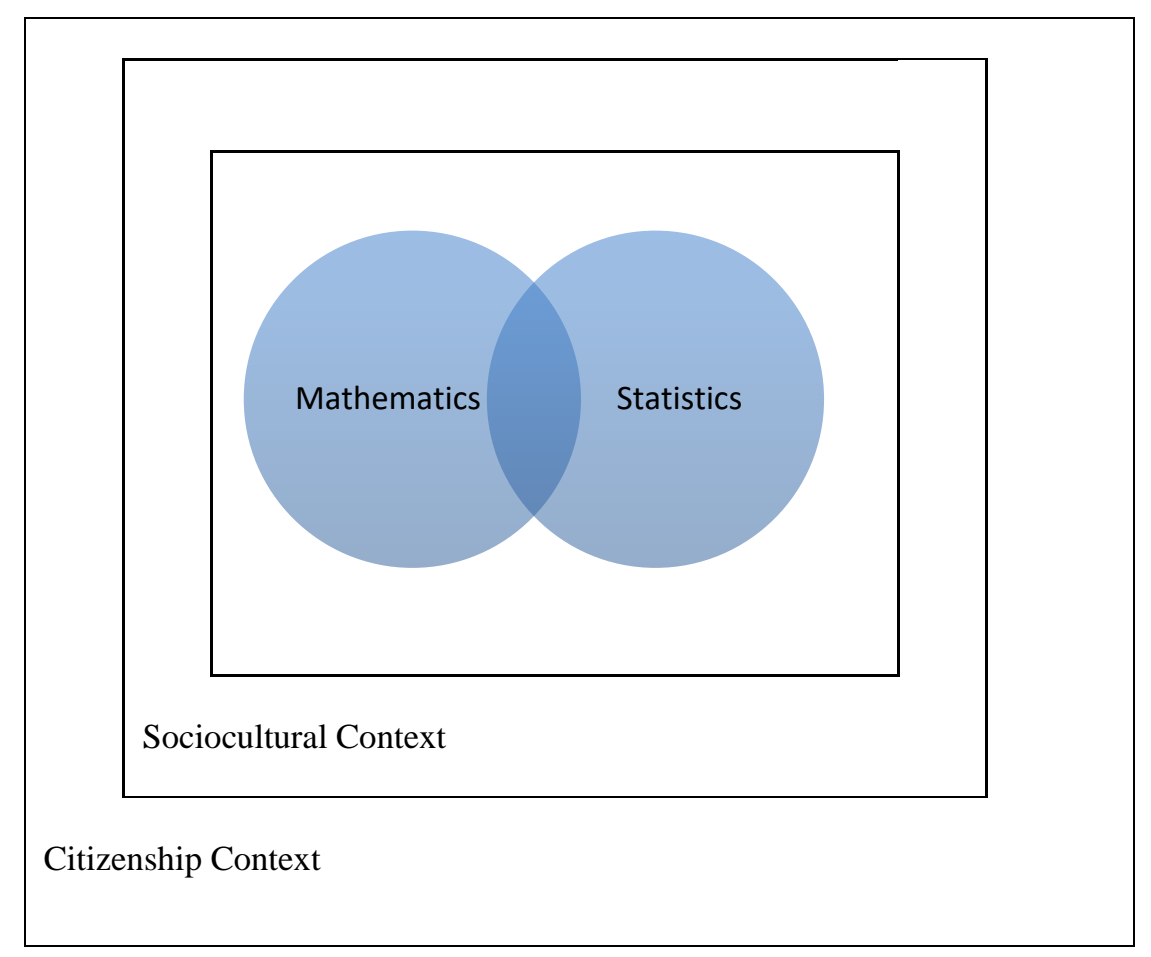

Figure 1. The interdisciplinary intersection between mathematics and statistics 
As for the links made by the teachers between statistics and mathematics, the context of the tasks and other disciplines, our data suggested opportunities to make those links. However, the teachers did not seem to see this as a priority in their lessons. For instance, Elsa and Chantale suggested that their students study a phenomenon using statistics, but what was highlighted was the process of doing mathematics instead of making sense of the data. The sociocultural context of the chosen problem was seen more as an alternative to implement statistics rather than a teaching and learning opportunity to develop statistical reasoning.

\subsection{TEACHERS’ REPRESENTATIONS OF STATISTICS}

As for the teachers' representations of statistics, the three emerging themes from our data suggest that their representations belong to different contexts. For instance, the first theme, displaying data collected, is situated in the intersection between the mathematical and the statistical contexts. It suggests the process of collecting and representing data with mathematical and statistical concepts embedded. The lessons we observed were aligned with this theme. The second theme, highlighting data, is situated in the statistical context. It suggests the process of analyzing data. However, the teachers' actions we observed were not particularly aligned with this theme. The third theme, data as needs or trends in society, is situated in the citizenship context. It suggests the use of statistics in developing citizenship. Thus, citizenship competencies should also include statistical literacy. We were not able to observe this in the teacher's lesson. In fact, our data suggest that the three teachers had limited visions of statistics, which mainly focused on some parts of basic literacy and thinking domains (delMas, 2002). All the interpretation aspects that lead to strong statistical reasoning, critical thinking, and decision-making processes were not promoted and fully presented in their lessons. As highlighted by the interrogative cycle presented by Wild \& Pfannkuch (1999), all three of these are strongly linked. Statistical reasoning contributes to the development of critical thinking, and critical thinking contributes to the development of statistical reasoning, because it is possible to use statistical reasoning when making judgments or making decisions, and also because the interrogative cycle could not be done using critical thinking. Decisionmaking processes are also present in some instructional goals. For instance, instructional goal 2 involves the decision-making process when formulating a survey question, organizing data and selecting a visual display. The ability to communicate statistically (instructional goal 7) also involves a decision-making process when generating questions or arguments for better communication. Understanding probability and chance (instructional goal 5) is an important component that relates to the decision-making process. Thus, a decision-making process is used not only when doing statistics, and statistical reasoning might be used in other contexts when making a decision.

\subsection{LIMITS AND IMPLICATIONS}

Multiple factors have possibly influenced our results. The fact that we only recommended to teachers to film one lesson is a possible limit to our study. The lessons that the teachers from NB recorded were only one part of a larger sequence of lessons. Also, the fact that we could use only the edited videos could have influenced the results. Institutional factors could have also contributed to our results. During the focus groups, all teachers mentioned that they like to innovate and try different things in class, but they felt pressures, such as provincial exams at the end of the year. 
The implications of our results show the epistemological differences between mathematics and statistics and the necessity to support teachers in developing knowledge about them. It is not enough to know how to apply, for example, instructional goal 3, it is also important to develop the knowledge behind the other 7 goals in order to develop a vision for teaching statistics: helping students to develop statistical reasoning for developing citizenship competencies.

\section{CONCLUSION}

Our study showed that the teachers we observed seemed to focus their attention on the procedural understanding of ideas in statistics, in this case creating pie charts adequately, which made the development of statistical reasoning more challenging. In addition, although we were able to observe some intra and interdisciplinary links in the lessons, they tended to highlight either statistics or mathematics as stand-alone subjects. The teachers' representations of statistics might have influenced the development of statistical reasoning in students and the creation of intra and interdisciplinary links in their statistics lessons. The tasks used seemed to be more open-ended when the teacher had a broader vision of statistics, such as having an impact in society. When the representations were more oriented toward procedural understanding instead of interpreting a phenomenon, the epistemologies were more aligned with a deterministic reasoning based on procedure rather than interpretative reasoning. More in-depth studies would be necessary to confirm this affirmation.

The results also highlighted the importance of treating statistics as an interdisciplinary subject. To develop statistical reasoning, students must be exposed to both intradisciplinary links between mathematical ideas, including probability and chance, and interdisciplinary links between mathematics, statistics and the sociocultural context involved. The model we suggested would be a possibility to explore further. Our results suggest a new direction for investigation.

\section{ACKNOWLEDGEMENTS}

This study was supported by the Social Sciences and Humanities Research Council of Canada.

\section{REFERENCES}

Ball, D.L., Thames, M.H., \& Phelps, G. (2008). Content knowledge for teaching: What makes it special? Journal of Teacher Education, 59, 389-407.

Boaler, J. (2009). What's math got to do with it?: How parents and teachers can help children learn to love their least favorite subject. New-York, NY: The Penguin Group.

Brun, J., \& Conne, F. (1990). Analyses didactiques de protocoles d'observation du déroulement de situations. [Didactical analysis of protocols for observing the progress of situations]. Education et Recherches (3), 261-285.

Carvalho, C., \& Solomon, Y. (2012). Supporting statistical literacy: What do culturally relevant/realistic tasks show us about the nature of pupil engagement with statistics? International Journal of Educational Research, 55, 57-65.

delMas, R. C. (2002). Statistical literacy, reasoning, and learning: A commentary. Journal of Statistics Education, 10(3). [Online :

http://www.amstat.org/publications/jse/v10n3/delmas discussion.html] 
delMas, R. C. (2004). A comparison of mathematical and statistical reasoning. In D. Ben Zvi \& J. Garfield (Eds.), The challenge of developing statistical literacy, reasoning, and thinking (pp. 79-95). Netherlands: Kluwer Academic Publishers.

Fourez, G., \& Larochelle, M. (2003). Apprivoiser l'épistémologie. [Tame epistemology]. Bruxelles: De Boeck.

Gal, I., \& Garfield, J. (1997). Curricular goals and assessment challenges in statistics education. In I. G. J. Garfield (Ed.), The assessment challenge in statistics education (pp. 1-13). Amsterdam: IOS Press.

Garfield, J. (2002). The challenge of developing statistical reasoning. Journal of Statistics Education, 10(3).

[Online: http://www.amstat.org/publications/jse/v10n3/garfield.html]

Halpern, Diane F. (2003). Thought and knowledge: An introduction to critical thinking ( $4^{\text {th }}$ ed.). Mahwah, New Jersey: Lawrence Erlbaum Associates.

Kader, G., \& Perry, M. (1994). Power on! Learning statistics with technology. Mathematics Teaching in the Middle School, 1(2), 130-136.

Knapp, M., Adelman, N., Marder, C., McCollum, H., Needels, C., Padilla, C., Shields, P., Turnbull, B., \& Zucker, A. (1995). Teaching for meaning in high-poverty classrooms. New York: Teachers College Press.

Legendre, R. (1993). Dictionnaire actuel de l'éducation. [Education dictionary]. 2e edition. Montréal: Guérin.

Lenoir, Y., \& Sauvé, L. (1998). L'interdisciplinarité et la formation à l'enseignement primaire et secondaire: quelle interdisciplinarité pour quelle formation? [Interdisciplinarity and initial elementary and secondary school teachers' preparation: Which interdisciplinarity for which initial preparation?]. Revue des Sciences de l'Éducation, 24(1), 3-29.

Lipman, M. (1995). À l'école de la pensée. [Thinking in Education]. Bruxelles: De Boeck.

Manuel, D. (2010). Étude de la créativité mathématique dans les solutions aux problèmes proposés dans la communauté virtuelle CASMI. [Study on mathematical creativity in solutions of problems posted in the virtual community CASMI]. (Maitrise-ès Arts en éducation (mention enseignement)), Université de Moncton, Moncton, NB, Canada.

Manuel, D., Freiman, V., \& Bourque, J. (2012). Richesse des problèmes posés et créativité des solutions soumises dans la Communauté d'apprentissages scientifiques et mathématiques interactifs (CASMI). [Wealth of problems posted and creativity of solutions submitted in the virtual community CASMI]. Éducation francophone en milieu minoritaire, 7(1), 1-18. Retrieved from

http://sites.ustboniface.ca/reefmm/Notrerevue/v7n1manuelfreimanbourque_000.pdf

Maturana, H. (1987) Everything said is said by an observer, in W. Thompson (Ed), Gaia: a way of knowing. Hudson, NY: Lindisfarne Press.

Ministère de l'Éducation du Québec . (2006). Québec education program. Secondary school education, Cycle one. Québec, QC, Canada: Gouvernement du Québec .

Ministère de l'Éducation et du Développement de la Petite Enfance du NouveauBrunswick. (2012). Programme d'études: Mathématiques au primaire 8e année. [Education program: Mathematics in elementary Grade 8]. Fredericton, NB, Canada: Gouvernement du Nouveau-Brunswick.

Mousley, J. (2004). An aspect of mathematical understanding: The notion of "connected learning”. In McDougall, D.E \& Ross, J. A. (Eds.). Proceedings of the Twenty-Sixth Annual Meeting of the North American Chapter of the International Group for the Psychology of Mathematics Education. (Vol. 3, pp. 377-384). Toronto, ON, Canada: PME. 
National Council of Teachers of Mathematics (NCTM). (2000). Principles and standards for school mathematics. Reston, VA: National Council of Teachers of Mathematics.

Piaget, J. (1976). La formation du symbole chez l'enfant (6 $6^{\text {th }}$ ed.). [The formation of the symbol in children]. Neuchâtel: Delachaux et Niestlé.

Pratt, D., Davies, N., \& Connor D. (2011). The role of technology in teaching and learning statistics. In C. Batanero, G. Burrill, \& C. Reading (Eds.), Teaching statistics in school mathematics-challenges for teaching and teacher education: A Joint ICMI/IASE Study (pp. 97-107). Springer

Reid, D. A., Simmt, E., Savard, A., Suurtamm, C., Manuel, D., Lin, T. W. J., \& Knipping, C. (2015). Observing teachers: Using video to prompt and record reflections on teachers' pedagogies in regions of Canada. Research in Comparative \& International Education, 10(3), 367-382.

Robert, A., Penninckx, J., \& Lattuali, M. (2012). Une caméra au fond de la classe de mathématiques: (se) former au métier d'enseignant du secondaire à partir d'analyses de vidéos. [A camera at the back of the mathematics class: training as a high school teacher from video analyzes]. Besançon, France: Presses universitaires de FrancheComté.

Samson, G. (2014). From writing to doing: The challenges of implementing integration (and interdisciplinarity) in the teaching of mathematics, science and technology. Canadian Journal of Science, Mathematics and Technology Education, 14(4), 346358.

Savard, A. (2008). Le développement d'une pensée critique envers les jeux de hasard et d'argent par l'enseignement des probabilités à l'école primaire: Vers une prise de décision. [The development of a critical thinking about gambling through the teaching of probabilities in primary school: Towards a decision-making process].Thèse inédite. Université Laval, Québec.

Savard, A., \& DeBlois, L. (2013). Enumerating all possible outcomes: An analysis of students' work. Scientia in Educatione, 4 (1), 49-62.

Savard, A. (2014). Developing probabilistic thinking: What about people's conceptions? In E. Chernoff \& B. Sriraman (Eds). Probabilistic thinking: Presenting plural perspectives. Vol. 2. (p 283-298). Berlin/Heidelberg, Springer.

Savoie-Zajc, L. (2000). La recherche qualitative/interprétative en éducation. [Qualitative/interpretative research in education]. In T. Karsenti \& L. Savoie-Zajc (Eds.), Introduction à la recherche en education. [Introduction to the research in education]. (pp. 171-198). Sherbrooke: Éditions du CRP.

Swartz, Robert J., \& Perkins, David N. (1990). Teaching thinking: Issues and approaches. Pacific Groves, CA: Midwest Publications.

ten Dam, G., \& Volman, M. (2004). Critical thinking as a citizenship competence: Teaching strategies. Learning and Instruction, 14(4), 359-379.

Tobin, J. (1988). Visual anthropology and multivocal ethnography: A dialogical approach to Japanese preschool class size. Dialectical Anthropology, 13(2), 173-187.

Tobin, J., Hsueh, Y., \& Karasawa, M. (2009) Preschool in three cultures revisited: China, Japan, and the United States. Chicago: University of Chicago Press.

Wild, C.D., \& Pfannkuch, M. (1999). Statistical thinking in empirical enquiry. International Statistical Review. 67(3), 223-265.

ANNIE SAVARD

Associate Professor

Department of Integrated Studies in Education Faculty of Education, McGill University 3700 McTavish Street, Room 309 
Montréal, Québec, Canada H3A 1Y2

P: 514-398-4527 ext: 094455

Fax: 514-398-4529 